Paidéia, 2006, 16(34), 169-179

\title{
BRINCADEIRA E DESENVOLVIMENTO INFANTIL: UM OLHAR SOCIOCULTURAL CONSTRUTIVISTA ${ }^{1}$
}

\author{
Norma Lucia Neris de Queiroz \\ Diva Albuquerque Maciel \\ Angela Uchôa Branco \\ Universidade de Brasília
}

\begin{abstract}
Resumo: Como e por que as crianças brincam? Qual o significado desta atividade em cada cultura? Estas questões da temática da brincadeira e sua relevância para a compreensão científica do desenvolvimento infantil são discutidas neste estudo. Analisa-se o conceito da atividade de brincar a partir de diferentes autores, privilegiando quem a vê como socialmente construída. Aborda-se a importância da brincadeira do faz-de-conta como atividade que promove a representação e a metarepresentação no desenvolvimento da criança. Finalmente reflete-se sobre a brincadeira no contexto pedagógico vivenciado pelas crianças em instituições de educação infantil, o papel do professor no desenvolvimento e educação infantil.
\end{abstract}

Palavras-chave: brincadeira; abordagem sociocultural; desenvolvimento infantil; educação infantil.

\section{PLAY AND CHILD DEVELOPMENT: A SOCIOCULTURAL CONSTRUCTIVIST APPROACH}

Abstract: How and why do children play? What does such activity means in different cultures? These issues are discussed in this present paper, which stresses its relevance for the scientific understanding of child development. The concept of play according to different theorists is analyzed; especially those that conceive play as socially constructed activity. It is verified the role of pretend-play as an activity of representation and metarepresentation along child development. Finally on discusse how such theoretical ideas can be translated into educational practices within the contexts of child care and preschool settings, stressing the role of teacher in promoting child development and education.

Key words: play; sociocultural approach; child development; early childhood education.

\section{Introdução}

Em grande parte das sociedades contemporâneas, a infância é marcada pelo brincar, que faz parte de práticas culturais típicas, mesmo que esteja muito reduzida face à demanda do trabalho infantil que ainda se insere no cotidiano dos segmentos sociais de baixa renda. A brincadeira permite à criança vivenciar o lúdico e descobrir-se a si mesma, apreender a realidade, tornando-se capaz de desenvolver seu potencial criativo (Siaulys, 2005). Nesta perspectiva, as que brincam aprendem a significar o pensamento dos parceiros por meio da metacognição, típica dos processos simbólicos que promovem o desenvolvimento da cognição (Kishimoto, 2002) e de dimensões que inte-

\footnotetext{
${ }^{1}$ Recebido em 23/06/06 e aceito para publicação em 20/10/06.

2 Endereço para correspondência: Diva Albuquerque Maciel, LABMIS, Programa de Pós-graduação em Psicologia em Desenvolvimento Humano e Saúde - PED/IP - UnB, Brasilia- DF, E-mail: diva@unb.br
}

gram a condição humana (Andrensen, 2005; Branco, 2005).

Para a maioria dos grupos sociais, a brincadeira é consagrada como atividade essencial ao desenvolvimento infantil. Historicamente, ela como lúdico sempre esteve presente na educação infantil, único nível de ensino que a escola deu passaporte livre, aberto à iniciativa, criatividade, inovação por parte dos seus protagonistas (Lucariello, 1995). Com o advento de pesquisas sobre o desenvolvimento humano, observou-se que o ato de brincar conquistou mais espaço, tanto no âmbito familiar, quanto no educacional; no Referencial Curricular Nacional para a Educação Infantil (1998), a brincadeira está colocada como um dos princípios fundamentais, defendida como um direito, uma forma particular de expressão, pensamento, interação e comunicação entre as cri- 
anças. Assim, a brincadeira é cada vez mais entendida como atividade que, além de promover o desenvolvimento global das crianças, incentiva a interação entre os pares, a resolução construtiva de conflitos, a formação de um cidadão crítico e reflexivo (Branco, 2005; DeVries, 2003; DeVries \& Zan, 1998; Tobin, Wu \& Davidson, 1989; Vygotsky, 1984, 1987).

Hoje, pode-se afirmar que já foi superado parte do equívoco, de que o conteúdo imaginário do brinquedo determinava a brincadeira da criança. Segundo Benjamin (1984),

"a criança quer puxar alguma coisa, torna-se
cavalo, quer brincar com areia e torna-se pa-
deiro, quer esconder-se, torna-se ladrão ou guar-
da e alguns instrumentos do brincar arcaico
desprezam toda a máscara imaginária (na épo-
ca, possivelmente vinculados a rituais): a bola,
o arco, a roda de penas e o papagaio, autênti-
cos brinquedos, tanto mais autênticos quanto
menos o parecem ao adulto." (pp. 76-77).

Para o autor, quando a criança brinca, além de conjugar materiais heterogêneos (pedra, areia, madeira e papel), ela faz construções sofisticadas da realidade e desenvolve seu potencial criativo, transforma a função dos objetos para atender seus desejos. Assim, um pedaço de madeira pode virar um cavalo; com areia, ela faz bolos, doces para sua festa de aniversário imaginária; e, ainda, cadeiras se transformam em trem, em que ela tem a função de conduto, imitando o adulto (Benjamin, 2002).

Neste trabalho, pretende-se olhar a temática da brincadeira enfatizando três aspectos: primeiro analisar-se-á o conceito da atividade de brincar a partir de autores que a vêem como construída social e culturalmente; segundo, será destacada a importância do faz-de-conta para o desenvolvimento da criança pequena; e, por fim será vista a brincadeira no contexto pedagógico vivenciado por crianças em instituições de educação infantil, com a intenção de orientar a atuação de professores deste nível de ensino.

\section{Conceito da Atividade de Brincar}

"A brincadeira é uma atividade que a criança começa desde seu nascimento no âmbito familiar" (Kishimoto, 2002, p. 139) e continua com seus pares. Inicialmente, ela não tem objetivo educativo ou de aprendizagem pré-definido. A maioria dos autores afirma que ela é desenvolvida pela criança para seu prazer e recreação, mas também permite a ela interagir com pais, adultos e coetâneos, bem como explorar o meio ambiente.

Como a criança é um ser em desenvolvimento, sua brincadeira vai se estruturando com base no que é capaz de fazer em cada momento. Isto é, ela aos seis meses e aos três anos de idade tem possibilidades diferentes de expressão, comunicação e relacionamento com o ambiente sociocultural no qual se encontra inserida. Ao longo do desenvolvimento, portanto, as crianças vão construindo novas e diferentes competências, no contexto das práticas sociais, que irão lhes permitir compreender e atuar de forma mais ampla no mundo.

A brincadeira das crianças evolui mais nos seis primeiros anos de vida do que em qualquer outra fase do desenvolvimento humano e neste período, se estrutura de forma bem diferente de como a compreenderam teóricos interessados na temática (Brougère, 1998). A partir da brincadeira, a criança constroi sua experiência de se relacionar com o mundo de maneira ativa, vivencia experiências de tomadas de decisões. Em um jogo qualquer, ela pode optar por brincar ou não, o que é característica importante da brincadeira, pois oportuniza o desenvolvimento da autonomia, criatividade e responsabilidade quanto a suas próprias ações.

O termo cultura é entendido aqui a partir das formulações teóricas de Valsiner (2000), para quem a cultura não se refere apenas a um grupo de indivíduos que compartilham características semelhantes, mas deve ser compreendida como mediação semiótica, que integra o sistema psicológico individual e o universo social das crianças dela participantes. É no contexto da cultura que se dá a construção social, de significados, com base nas tradições, idéias e valores do grupo cultural que cria e recria padrões de participação, dando origem ao desenvolvimento de típicas categorias de pensamento e de recursos de expressão.

Fein (Spodek \& Saracho, 1998) afirma que é muito "difícil definir a brincadeira, mas, em certo sentido, ela se auto-define" (p. 210). A preocupação em conceituar o que é a brincadeira não é apenas dos educadores, mas está na pauta de outros profissionais, dentre eles psicólogos, filósofos, historiadores e antropólogos. 
No 'Ciclo de Debates sobre o Brincar'", Carvalho, Salles, Guimarães e Debortoli (2005), observaram a diversidade de discursos e concepções do ato de brincar. Examinando essa questão, Spodek e Saracho (1998) apontam que a dificuldade em se chegar a uma definição consensual sobre a brincadeira advém da falta de critérios para se classificar uma atividade como tal; assim, em alguns contextos ou momentos uma atividade pode ser considerada brincadeira, e deixar de sê-lo em outros, o que depende da relação que se estabelece com a situação, do significado que assume para quem brinca.

Vygotsky (1998), um dos representantes mais importantes da psicologia histórico-cultural, partiu do princípio que o sujeito se constitui nas relações com os outros, por meio de atividades caracteristicamente humanas, que são mediadas por ferramentas técnicas e semióticas. Nesta perspectiva, a brincadeira infantil assume uma posição privilegiada para a análise do processo de constituição do sujeito; $r$

.ompendo com a visão tradicional de que ela é atividade natural de satisfação de instintos infantis, o autor apresenta o brincar como uma atividade em que, tanto os significados social e historicamente produzidos são construídos, quanto novos podem ali emergir. A brincadeira e o jogo de faz-de-conta seriam considerados como espaços de construção de conhecimentos pelas crianças, na medida em que os significados que ali transitam são apropriados por elas de forma específica.

Vygotsky (1998), quando discute em sua teoria a gênese e o desenvolvimento do psiquismo humano, destaca que o processo de significação é elaborado por meio da atividade em contextos sociais específicos; o que é interiorizado não é a 'realidade em si mesma' (conceito já ultrapassado na perspectiva socio-construcionista), mas o que esta significa tanto para os sujeitos em relação, quanto para cada um em particular. Este movimento de interiorização transformadora das significações não se dá de maneira passiva nem direta, pois o sujeito reelabora, imprimindo sentidos privados ao significado compartilhado na cultura. Nesse processo ele se apropria do signo em sua função de significação, observando seu

\footnotetext{
${ }^{1}$ Universidade Federal de Minas Gerais,em 2003 e 2004,publicado no livro Brincares, em 2005,
}

duplo referencial semântico, um formado pelos sistemas construídos ao longo da história social e cultural dos povos, e o outro formado pela experiência pessoal e social, evocada em cada ação ou verbalização do sujeito.

Para Vygotsky (1998), a criança nasce em um meio cultural repleto de significações social e historicamente produzidas, definidas e codificadas, que são constantemente ressignificadas e apropriadas pelos sujeitos em relação, constituindo-se, assim, em motores do desenvolvimento. Neste sentido, o desenvolvimento humano para ele se distancia da forma como é entendido por outras teorias psicológicas, por ser visto como um processo cultural que ocorre necessariamente mediado por um outro social, no contexto da própria cultura, forjando-se os processos psicológicos superiores, sendo a psique humana, nesta perspectiva, essencialmente social.

Os processos psicológicos superiores para Vygotsky (1987) são constituídos

(...) pelos de domínio dos meios externos do
desenvolvimento cultural e do pensamento: o
idioma, a escrita, o cálculo, o desenho, bem
como pelas funções psíquicas superiores espe-
ciais, aquelas não limitadas nem determina-
das de nenhuma forma precisa e que têm sido
denominadas pela psicologia tradicional com
os nomes de atenção voluntária, memória ló-
gica e formação de conceitos (p. 32).

O autor afirma, ainda, que o desenvolvimento humano é um processo dialético, marcado por etapas qualitativamente diferentes e determinadas pelas atividades mediadas. O homem, enquanto sujeito é capaz de transformar sua própria história e a da humanidade, uma vez que por seu intermédio muda o contexto social em que se insere, ao mesmo tempo em que é modificado.

Assim, o que caracteriza a atividade humana é o emprego de instrumentos, signos ou ferramentas, que lhe dão um caráter mediado. Entretanto, instrumentos e signos são coisas diferentes; os primeiros influenciam a ação humana sobre a atividade e são externamente orientados. Já os segundos não modificam em nada o objeto da atividade, mas se constituem em ferramenta interna dirigida ao controle do indivíduo, sendo orientados internamente. 
Desta maneira, os objetos com os quais a criança se relaciona são significados em sua cultura e a relação estabelecida com eles se modifica à medida em que a ela se desenvolve. Em um primeiro momento esta relação é marcada pela predominância de sentidos convencionais, característicos da cultura em que está inserida; o objeto, de certa forma, diz para a criança como deve agir. Com o passar do tempo, de modo gradativo, a relação entre objeto significado e ação se altera, tendo a brincadeira um lugar de destaque nessa mudança.

A importância do brincar para o desenvolvimento infantil reside no fato de esta atividade contribuir para a mudança na relação da criança com os objetos, pois estes perdem sua força determinadora na brincadeira. "A criança vê um objeto, mas age de maneira diferente em relação ao que vê. Assim, é alcançada uma condição que começa a agir independentemente daquilo que vê." (Vygotsky, 1998, p. 127).

$\mathrm{Na}$ brincadeira, a criança pode dar outros sentidos aos objetos e jogos, seja a partir de sua própria ação ou imaginação, seja na trama de relações que estabelece com os amigos com os quais produz novos sentidos e os compartilha (Cerisara, 2002).

A brincadeira é de fundamental importância para o desenvolvimento infantil na medida em que a criança pode transformar e produzir novos significados. Em situações dela bem pequena, bastante estimulada, é possível observar que rompe com a relação de subordinação ao objeto, atribuindo-lhe um novo significado, o que expressa seu caráter ativo, no curso de seu próprio desenvolvimento.

Para Vygotsky (1998), a criação de situações imaginárias na brincadeira surge da tensão entre o indivíduo e a sociedade e a brincadeira libera a criança das amarras da realidade imediata, dando-lhe oportunidade para controlar uma situação existente (Cerisara, 2002). As crianças usam objetos para representar coisas diferentes do que realmente são: pedrinhas de vários tamanhos podem ser alimentos diversos na brincadeira de casinha, pedaços de madeira de tamanhos variados podem representar diferentes veículos na estrada. Na brincadeira, os significados e as ações relacionadas aos objetos convencionalmente podem ser libertados. As crianças utilizam processos de pensamento de ordem superior como no jogo de faz-de-conta, que assume um papel central no desenvolvimento da aquisição da linguagem e das habilidades de solução de problemas por elas (Meira, 2003).

Vygotsky (1998) definiu a zona de desenvolvimento proximal (ZPD) como:

(...) a distância entre o nivel de desenvolvi-
mento real, que se costuma determinar através
da solução independente de problemas, e o
nivel de desenvolvimento potencial, determi-
nado através da solução de problemas sob a
orientação de um adulto ou em colaboração
com os companheiros mais capazes (p.97).

A brincadeira é, assim, a realização das tendências que não podem ser imediatamente satisfeitas. Esses elementos da situação imaginária constituirão parte da atmosfera emocional do próprio brinquedo. Nesse sentido, a brincadeira representa o funcionamento da criança na zona proximal e portanto, promove o desenvolvimento infantil (Vygotsky, 1998). Entretanto, Vygotsky chama a atenção quando afirma que definir "o brinquedo como uma atividade que dá prazer à criança, é incorreto" (p. 105), porque para ele, muitas atividades dão à criança prazeres mais intensos que a brincadeira: por exemplo, uma chupeta para um bebê mesmo que isso não leve à saciação da fome. Ele destaca, ainda, que há brincadeiras em que a própria atividade não é tão agradável, como as que só agradam às crianças (entre cinco e seis anos de idade) se elas considerarem o resultado interessante. Os jogos esportivos podem ser outro exemplo (não apenas os esportes atléticos, mas os que têm como regra, ganhadores e perdedores). Estes são freqüentemente acompanhados de desprazer para a criança que não alcança o resultado favorável, isto é, aquela que perde a partida.

Assim, o prazer não pode ser visto como uma característica definidora da brincadeira (Cerisara, 2002). Entretanto, não se deve ignorá-lo, pois ela preenche necessidades da criança e cria incentivos para colocá-la em ação, que é de fundamental importância, uma vez que contribui para mudanças nos níveis do desenvolvimento humano. Para Cerisara (2002), todo avanço nestes está relacionado a alterações acentuadas nas motivações, tendências e incentivos. Torna-se, então, necessário lembrar que os interesses 
mudam em função do desenvolvimento e da maturidade do sujeito, pois, o que atrai um bebê não o faz a uma criança um pouco mais velha. Portanto, a maturidade das necessidades é um tópico importante na teoria da Psicologia histórico-cultural.

Vygotsky (1998) afirma que não é possível ignorar que a criança satisfaz algumas necessidades por meio da atividade do brincar. As pequenas tendem a satisfazer seus desejos imediatamente, e o intervalo entre desejar e realizar, de fato, é bem curto. Já as crianças entre dois e seis anos de idade são capazes de inúmeros desejos, e muitos não podem ser realizados naquele momento, mas posteriormente por meio de brincadeiras. Vygotsky (1998) diz que,

(...) se as necessidades não realizáveis imediatamente, não se desenvolvessem durante os anos escolares, não existiriam os brinquedos, uma vez que eles parecem ser inventados justamente quando as crianças começam experimentar tendências irreali-záveis (p. 106).

Com isto, no espaço da sala de aula, a criança procura satisfazer seus desejos não realizáveis imediatamente envolvendo-se em um mundo imaginário, onde os não realizáveis podem ser concretizados; a este mundo é que se chama da brincadeira. $\mathrm{O}$ autor concebe a imaginação como:

(...) um processo psicológico novo para a criança em desenvolvimento; representa uma forma especificamente humana de atividade consciente, não está presente na consciência de crianças muito pequenas e está totalmente ausente em animais. Como todas as funções da consciência, ela surge originariamente da ação e na interação com o outro (p. 106).

Há, portanto, uma crença de senso comum que o brincar da criança é imaginação em ação. Vygotsky (1998) considera que isto deveria ser invertido, uma vez que a imaginação, nas crianças em idade da educação infantil e nos adolescentes, é o brinquedo sem ação. Desta forma, fica claro que o prazer que estas vivenciam é controlado por motivações diferentes das experimentadas por um bebê ao chupar sua chupeta.

Para o autor, nem todos os desejos não satisfeitos dão origem à brincadeira; quando uma criança quer andar de velocípede e isto não pode ser imediatamente concretizado, ela não vai para seu quarto e faz de conta que está andando de velocípede para satisfazer seu desejo, pois não tem consciência das motivações e emoções que dão origem à brincadeira. Nessa perspectiva, Vygotsky (1998) diz que o brinquedo difere muito do trabalho e de outras formas de atividade, uma vez que nele a criança cria uma situação imaginária, algo reconhecido pelos estudiosos, e que portanto não é novo. Ele afirma que a imaginação é característica definidora da brincadeira e não um atributo de subcategorias específicas do brinquedo.

Cerisara (2002) coloca que toda situação imaginária que envolve o brinquedo já pressupõe regras, ocultas ou não e que o contrário é verdadeiro, ou seja, todo jogo tem, explicitamente ou não, uma situação imaginária envolvida. Nesse sentido, o faz-de-conta é em especial significativo para o desenvolvimento infantil, por estar relacionado à imaginação.

Em um esforço para compreender a importância da atividade do brincar para o desenvolvimento infantil, numa perspectiva co-construtivista, pode-se considerar que a criança, desde seu nascimento, se integra em um mundo de significados construídos historicamente. É por meio da interação com seus pares que ela se envolve em processos de negociação, dentre os quais, os de significação e re-significação de si mesma, dos objetos, dos eventos e de situações, construindo e reconstruindo ativamente novos significados.

Valsiner (1988) acrescenta que para analisar o desenvolvimento infantil deve-se considerar os ambientes em que ocorre a atividade da brincadeira, que são fisicamente estruturados, segundo os significados culturais das pessoas responsáveis pela criança. Valsiner (2000) aponta, ainda, que ela ocupa um papel ativo na organização de suas atividades, construindo uma versão pessoal dos eventos sociais que lhe são transmitidos pelos membros de sua cultura. Esta construção é elaborada pelos processos de interação social, canalização e trocas, fazendo uso de recursos e instrumentos semióticos co-construídos, cujos significados estão presentes na "cultura coletiva". Por último, o autor afirma que é preciso considerar que a criança expressa a compreensão do mundo por meio da ação, e que cada classe social tem um sistema de significação cultural próprio, relacionado às práticas típicas de seu grupo. 


\section{Norma Lucia Neris de Queiroz}

Pedrosa (1996), em consonância com Valsiner, afirma que a criança desde o seu nascimento interage com um mundo de significados construídos historicamente; na relação com seus parceiros sociais se envolve em processos de significação de si, dos outros e dos acontecimentos de seu contexto cultural, construindo e reconstruindo ativamente significados.

Nessa perspectiva, destaca-se a importância de interpretar a brincadeira levando em consideração os contextos sociais específicos em que ela ocorre, não sendo possível separá-la artificialmente deles; e, para compreendê-la, deve-se relacionar o valor e o lugar que lhe são determinados pela cultura específica, porque só levando esta em consideração é que será possível derivar o significado do brincar infantil em cada uma.

Assim, a percepção infantil sobre a atividade de brincar é marcada pela influência cultural, que se torna o elemento de mediação que integra o sistema de funções psicológicas desenvolvidas pelo indivíduo na organização histórica de seu grupo social, por meio dos processos de interação, canalização e trocas, utilizando recursos e instrumentos semióticos coconstruídos de uma geração mais velha, com os quais a criança entra em contato.

A cultura, na concepção de Valsiner (2000), refere-se à organização estrutural de normas sociais, valores, regras de conduta e sistemas de significados compartilhados pelas pessoas que pertencem a certo grupo com uma história de convivência e relações de pertencimento. Para ele, a cultura tem duas faces: a) como entidade coletiva (significados compartilhados); b) como entidade pessoal (significados pessoais). A primeira é aprendida pela criança no contexto de suas experiências em diferentes tipos de ambientes. Especialmente os pais e profissionais responsáveis pelos cuidados e educação (escola, creches), devem procurar organizar o ambiente de forma que este seja brincável, isto é, explorável (Dantas, 2002), e que incentive o brincar.

É impossível, porém, a criança fazer a brincadeira em um âmbito apenas relacionado à livre fantasia; mesmo quando não imita os instrumentos dos adultos, sempre parte de significados culturalmente construídos, pois é deles que ela recebe seus primeiros brinquedos, embora tenha certa liberdade para aceitar ou recusar sugestões, muitos (bola, bonecas, carrinhos) são, de certa forma, impostos como objetos de valor, e daí, graças à força de sua imaginação, são transformados em brinquedos admirados e maravilhosos (Benjamin, 2002).

As crenças dos adultos sobre a brincadeira infantil são geradas em seus sistemas de significado cultural. Neste sentido, Valsiner (1988) destaca que a criança, como ser ativo, no processo 'viver a brincadeira', vai além da cultura de seus pais e professores, uma vez que reconstrói as experiências adquiridas nos espaços familiares, escolares e comunitários. Ela, assim, cria, para suas brincadeiras, funções e cenários novos para as sugestões sociais, oferecidas por seu grupo; assim, ela externaliza sua subjetividade sobre os eventos sociais e, ao mesmo tempo, reconstrói o significado social da brincadeira.

A subjetividade da criança vai se formando nas interações que estabelece com seus parceiros nos contextos cotidianos. Valsiner (1989) acrescenta que o mundo adulto, dependendo de seus valores culturais, oferece à criança uma variedade de sugestões e modos de interação semioticamente marcados pelos modelos sexuais, muitas vezes estereotipados como masculino, feminino ou indiferenciado. Esta é uma das sugestões sociais que levam a criança a brincadeiras marcadas pelo gênero, de acordo com a cultura coletiva, o que frequentemente ocorre naqueles em que o menino só pode brincar de carrinho, e menina, de casinha de boneca. As famílias canalizam as ações, as percepções e representações da criança na direção de assumir um papel social aprovado de acordo com suas crenças e valores.

Para Packer (1994) brincar é uma atividade prática, "na qual a criança constrói e transforma seu mundo, conjuntamente, renegociando e redefinindo a realidade" (p. 273); "uma construção da realidade, a produção de um mundo e a transformação do tempo e do lugar em que ele pode acontecer" (p. 271). A participação da criança nesta atividade "requer um senso de realidade compartilhado do que é verdadeiro ou falso, certo ou errado" (p.271).

Nas afirmações de Valsiner $(1998,2000)$ e de Pedrosa (1996), a criança é um sujeito ativo da coconstrução cultural, o que garante que a cultura de sua geração ultrapasse a dos adultos por ela respon- 
sáveis. Nesta perspectiva, torna-se necessário olhar a brincadeira para além do conceito da atividade de brincar, e examinar o faz-de-conta, que tem despertado especial interesse de teóricos, pesquisadores e profissionais que atuam com a educação infantil, lembrando a importância dada por Bateson (1972) quando se refere aos processos de metacomu-nicação, por meio dos quais as crianças se comunicam entre si, indicando se uma interação deve ser interpretada como "luta" - fisionomia séria, sem sorriso, ou "brincadeira"- sorriso, gargalhadas, gritinhos de alegria.

\section{Olhando a Brincadeira de Faz-de-Conta}

Dentre as brincadeiras realizadas pelas crianças, na faixa etária dos três aos sete anos, o faz-deconta é a que mais desperta o interesse e tem sido estudada em detalhes. Alguns pesquisadores que trabalham com as teorias do desenvolvimento cognitivo destacam a sua importância como comunicação integrada, ou seja, o faz-de-conta é uma atividade complexa e constituinte do sujeito, diferente das que caracterizam o cotidiano da vida real, que já aparece nos jogos de esconde-esconde que ela tem com os adultos, quando aprende que desaparecer, no jogo, não é algo real, mas inventado para poder brincar (Oliveira, 1996). Piaget (1978), face ao desenvolvimento do pensamento infantil, afirma que a brincadeira de faz-de-conta:

"está intimamente ligada ao símbolo, uma vez que por meio dele, a criança representa ações, pessoas ou objetos, pois estes trazem como temática para essa brincadeira o seu cotidiano (contexto familiar e escolar) de uma forma diferente de brincar com assuntos fictícios, contos de fadas ou personagens de televisão (p.76).

Neste sentido, ele diz que o pensamento da criança pequena não é suficientemente preciso e maleável para comunicar um conjunto de idéias, então, o símbolo assume a função de mediador, dando oportunidade à criança de expressar seu pensamento.

Para Vygotsky (1998), a brincadeira de fazde-conta cria uma zona de desenvolvimento proximal, pois no momento que a criança representa um objeto por outro, ela passa a se relacionar com o significado a ele atribuído, e não mais com ele em si. Assim, a atividade de brincar pode ajudar a passar de ações concretas com objetos para ações com outros significados, possibilitando avançar em direção ao pensamento abstrato. Tanto Piaget quanto Vygotsky concebem o faz-de-conta como atividade muito importante para o desenvolvimento.

Recentemente, estudiosos têm argumentado que o faz-de-conta não é apenas atividade representativa, mas metarepresentativa. A teoria da mente se preocupa em investigar "as habilidades das crianças pré-escolares de compreenderem seus próprios estados mentais e os dos outros e dessa maneira, predizerem suas ações ou comportamentos" (Jou \& Sperb, 1999, p. 292). Este interesse levou Sperb e Conti (1998), a realizarem um estudo com 14 tríades de crianças integradas à pré-escola, com idade média de 5 anos e 2 meses, para verificar se este grupo apresentaria habilidades metarepresentativas na brincadeira de faz-de-conta, aqui entendida não "mais como uma representação do mundo de uma forma direta, mas sim, representações de representações" (Jou \& Sperb, 1999, p.294), tomando como referência para análise as atividades do início da brincadeira e o relacionamento com os termos mentais a partir das categorias:a) as formas "planejadas"; b) o "entender o faz-de-conta no outro", c) as conceituadas como de termos mentais, ou seja, "expressão do desejo", "direção da interação", "modulação da asserção" e "expressão do estado mental".

Os resultados desse estudo evidenciaram que as crianças utilizaram mais as atividades de metarepresentação em relação às categorias "formas planejadas" e o "entender o faz-de-conta no outro" que as de termos mentais: "expressão do desejo", "direção da interação", "modulação da asserção" e "expressão do estado mental"; e mais a categoria de "expressão do desejo" que a "direção de interação". Concluiu-se que a atividade metarepresentativa apresentou-se tanto na brincadeira faz-de-conta quanto no uso de termos mentais das pré-escolares investigadas. Portanto, nessa faixa etária, ela pode possuir uma teoria da mente, à medida que evidencia a habilidade em entender a sua e a dos outros.

Com relação ao faz-de-conta, Sperb e Conti (1998) discutem a categorização, que coloca três como essenciais: A primeira quando a criança utiliza representações primárias, isto é, vê o mundo de forma di- 
reta e imediata, substituindo o objeto, por exemplo a mãe, pelo pai. Já a segunda, mais complexa, emerge quando ela usa representações secundárias, entendidas como representações de representações ou metarepresentações, atribuindo propriedades imaginárias aos objetos ou eventos, o que ocorre quando ela em interação com um parceiro lhe propõe que faça de conta que o tempo hoje está ótimo (quando está chovendo) ou que limpe o rosto da boneca que está sujo (sem estar). Neste momento, ela vai além do significado comum dos objetos ou dos eventos sem, entretanto, confundir realidade/não-realidade. Por último, em uma das formas mais avançadas do faz-de-conta, o objeto é imaginário, por exemplo "Faz-de-conta que neste prato tem bolo, neste copo, refrigerante".

Observa-se na categorização de Sperb e Conti (1998) que o faz-de-conta é uma brincadeira que além de envolver a operação de processos mentais, requer também a metarepresentação, pois a propriedade de opacidade suspende o compromisso com referência à "verdade". Assim, ele oferece as primeiras pistas de que a criança possui a habilidade de entender sua própria mente e a dos outros, como mostram os resultados do estudo citado.

A criança é capaz de entender o faz-de-conta e usar processos mentais de forma representacional a partir dos três anos de idade (Andrensen, 2005; Branco, 2005). E é nessa faixa etária que ela passa a dar maior importância ao grupo de pares (Eckerman \& Peterman, 2001). O faz-de-conta social implica em negociação; para brincar com outra sobre um mesmo tema, a criança precisa de um acordo quanto aos significados implícitos nos papéis e ações, caso contrário, a brincadeira não ocorrerá em grupo. Sendo assim, as transformações realizadas sobre os objetos precisam ser acompanhadas pelos parceiros e, para fazer parte da brincadeira, deve haver a aceitação dos papéis e/ou formas de negociação.

Sendo a brincadeira atividade estruturadora e impulsionadora do desenvolvimento infantil, as propostas educacionais que vêm sendo feitas para a educação desta faixa etária têm reconhecido a sua importância no contexto da sala de aula (Leme, 2005).

O Referencial Curricular Nacional para a Edu- cação Infantil (MEC, 1998) estabeleceu a brincadeira como um de seus princípios norteadores, que a define como um direito da criança para desenvolver seu pensamento e capacidade de expressão, além de situá-la em sua cultura. Atividades de brincadeira na educação infantil são praticadas há muitos anos, entretanto, torna-se imprescindível que o professor distinga o que é brincadeira livre e o que é atividade pedagógica que envolve brincadeira. Se quiser fazer brincadeiras com a turma, deve considerar que o mais importante é o interesse da criança por ela; se seu objetivo for a aprendizagem de conceitos, habilidades motoras, pode trabalhar com atividades lúdicas, só que aí não está promovendo a brincadeira, mas atividades pedagógicas de natureza lúdica.

Quando é mantida a especificidade da brincadeira livre, têm-se elementos fundamentais que devem ser considerados: a incerteza, a ausência de conseqüência necessária e a tomada de decisão pela criança; ela emerge como possibilidade de experimentação, na qual o adulto propõe, mas não impõe, convida, mas não obriga, e mantém a liberdade dando alternativas (Dantas, 2002). Caso contrário arrisca-se destruir o interesse da criança, tendo em vista que neste momento ela domina o espaço de experiência, mas o professor pode até interferir na brincadeira livre, desde que não utilize estratégia destrutiva do interesse dela.

Essa intervenção dá-se em dois níveis: De um lado, a não destrutiva do interesse pelo brinquedo; Do outro, a proposição, no momento propício e em associação com a brincadeira, de atividades dirigidas que tenham uma lógica, elaborada em função de objetivos pedagógicos, intencionalmente promovidos pelos educadores, tornando-se cada vez mais importantes à medida que a criança cresce. Intervir na brincadeira nunca dá certeza do que vai acontecer, mas deve ser assegurada a intenção de a atividade continuar a beneficiar o grupo.

Cabe ao professor, como adulto mais experiente, estimular brincadeiras, ordenar o espaço interno e externo da escola, facilitar a disposição dos brinquedos, mobiliário, e os demais elementos da sala de aula. Outras formas de intervenção podem ser propostas visando incitar as crianças a desenvolverem brincadeira nesta ou naquela direção, mas só como 
incitações, nunca obrigação, deixando-as tomarem a decisão de se engajarem na atividade.

O professor também pode brincar com as crianças, principalmente se elas o convidarem, solicitando sua participação ou intervenção. Mas deve procurar ter o máximo de cuidado respeitando sua brincadeira e ritmo; sem dúvida, esta forma de intervenção é delicada, por ser difícil o adulto participar da brincadeira sem destruí-la; é preciso muita sensibilidade, habilidade e bom nível de observação para participar de forma positiva.

A chave desta intervenção é a observação das brincadeiras das crianças, pois é necessário respeitálas: conhecê-las, sua cultura, como e com quê brincam, e quando seria interessante o adulto participar. Melhor, porém, é que não o faça e aproveite este momento para observar seus alunos, para conhecêlos melhor.

É também importante o professor desenvolver atividades dirigidas que envolvam brincadeiras, mas elas precisam ter seus temas relacionados para que haja contribuição para o desenvolvimento infantil; e elas atuando em conjunto podem, as duas serem enriquecidas.

Outra forma que o professor pode usar para enriquecer a brincadeira é propondo atividades que incentivem a curiosidade das crianças; por exemplo, a troca de cartas e bilhetes com os parceiros, leva à escrita e comunicação, sendo experiências que poderão ajudar a criança, mais adiante, a investir nestas habilidades no faz-de-conta.

O professor poderá, igualmente, organizar atividades que ajudem a criança a descobrir as possibilidades que certos materiais possuem; os jogos de grupo para crianças mais velhas, ou os de construção para as mais novas, ensinam a dominá-lo melhor, desenvolvendo outros níveis de competência, além de permitir verificar o interesse da criança.

Para Valsiner (2000), a brincadeira ocorre em ambientes que são fisicamente estruturados de acordo com os sistemas de significado cultural das pessoas que os habitam. Muitas crianças que sabem brincar descobriram e aprenderam isto em seu meio, com familiares, pares da mesma idade ou um pouco mais velhos; sendo a brincadeira uma atividade construída social e culturalmente em cada meio.

Outro aspecto importante é estimular as crianças a proporem brincadeiras que realizam em sua comunidade. Isto possibilitará que entre em sala de aula todo o universo cultural próprio dela, permitindo ao professor melhor conhecer sua realidade, cabendo a ele enriquecer as experiências lúdicas das crianças, pois a escola tem um grande número de crianças da mesma faixa etária, adultos mais experientes, materiais e espaços pensados para permitir atividades de natureza lúdica. Este enriquecimento pode ser desenvolvido por meio de: intervenções, ordenamento do espaço, atividades dirigidas que possibilitem o surgimento de novos elementos culturais, que permitirão às crianças integrá-los às suas brincadeiras.

\section{Considerações Finais}

$\mathrm{O}$ tema da brincadeira vem sendo bastante pesquisado, desde o século XVIII em suas diferentes vertentes. Apesar disso, percebem-se, ainda, lacunas de conhecimentos sobre o conceito e os processos envolvidos na brincadeira. A maior preocupação, no entanto, não deve se estabelecer um conceito universal e fechado sobre a atividade do brincar, mas ampliar as pesquisas, buscando preencher as lacunas existentes e, paralelamente, subsidiar os docentes e interessados no assunto para que possam realizar práticas educativas mais interessantes.

Com isso, $o$ ato de brincar, uma ação mediada pelo contexto sociocultural e o significado construído pela criança sobre a função de determinados objetos e da sua participação em certas brincadeiras, não é estático. De um lado existe dependência dos sistemas de significação coletivamente compartilhados pelo grupo a que a criança pertence, envolvendo crenças e valores dos adultos responsáveis por ela (mãe ou professora).

De outro lado, existe a versão construída pela criança sobre os padrões sociais, a partir dos referenciais transmitidos pelo grupo a que pertence, mas que são ressignificados no seu cotidiano e nas suas interações com seus pares e com 'outros sociais'. Desta forma, a criança recria seu espaço de brincadeira, com novos cenários, inventando funções para os objetos, dando-lhe um sentido de acordo com os padrões aprovados socialmente. 
A brincadeira oferece às crianças uma ampla estrutura básica para mudanças das necessidades e tomada de consciência: ações na esfera imaginativa, criação das intenções voluntárias, formação de planos da vida real, motivações intrínsecas e oportunidade de interação com o outro, que, sem dúvida contribuirão para o seu desenvolvimento.

Portanto, é imprescindível que os professores compreendam a importância da brincadeira e suas implicações para organizar o processo educativo de modo mais positivo, contribuindo para o desenvolvimento das crianças (Pontes \& Magalhães, 2003). Sem esta compreensão, corre-se o risco de uma prática educativa com equívocos, como por exemplo, professores preocupados em desenvolver a brincadeira em sala de aula, objetivando atitudes de cooperação entre os alunos, mas direcionando a atividade para a competição. No estudo de Palmieri (2003), os professores confundem cooperação e competição, e geralmente não percebem estes equívocos, acreditando que realizam um trabalho de grande qualidade para a formação dos alunos e se estes não correspondem às suas expectativas, apontam a eles como incapazes ou rotulam sua família como problemática. Nesse caso, o professor não está conseguindo fazer uma reflexão crítica do seu próprio trabalho.

Os princípios norteadores da política educacional congelados no papel não provocarão mudanças no contexto educacional. Mas, a administração pública deve proporcionar uma formação continuada aos professores; diante de situações de insegurança, isto é, de ministrar novos conteúdos e realizar propostas educativas que exigem conhecimentos diferentes dos que os profissionais acreditam, a tendência dos educadores é desprezá-las, muitas vezes fazendo críticas infundadas, apesar de reconheceram a importância dos novos conteúdos para o processo de melhoria da qualidade de ensino. É preciso que o professor reconheça a importância do princípio da brincadeira para o desenvolvimento infantil, estabelecido no Referencial Curricular Nacional para a Educação Infantil, como uma conquista e efetivação dos direitos da criança integrada à modalidade de educação infantil.

\section{Referências}

Andresen, H. (2005). Role play and language development in the preschool years. Culture \& Psychology, v.11 n.4, 387-414.

Bateson, G. (1972). Steps to an ecology of mind. New York: Chandler.

Benjamin, W. (1984). Reflexões: a criança, o brinquedo e a educação. São Paulo: Summus.

Benjamin, W. (2002). Rua de mão única. São Paulo: Brasiliense.

Branco, A.U. (2005). Peer interactions, language development and metacommunication. Culture \& Psychology, v.11 n.4, 415-430.

Brougère, G. (1998). Brinquedo e Cultura. São Paulo: Cortez.

Carvalho, A., Salles, F., Guimarães, M. \& Debortoli, J.A. (2005). Brincares. Belo Horizonte: UFMG.

Cerisara, A. B. (2002). De como o Papai do Céu, o Coelhinho da Páscoa, os anjos e o Papai Noel foram viver juntos no céu. Em T. M. Kishimoto (Org.), O brincar e suas teorias (pp.123-138). São Paulo: Pioneira-Thomson Learning.

Dantas, H. (2002). Brincar e trabalhar. Em T. M. Kishimoto (Org.), O brincar e suas teorias (pp.111-121). São Paulo: Pioneira-Thomson Learning.

Devries, R. (2003). Currículo Construtivista na Educação Infantil. Porto Alegre: ArtMed.

Devries, R. \& Zan, B. (1998). A ética na educação infantil. Porto Alegre: ArtMed.

Eckerman, C. \& Peterman, K. (2001). Peer and infant social/communicative development. In G. Bremner \& A. Fogel (Eds.), Peer relashionships and social skills in childhood (pp. 41 -71). New York: Springer.

Kishimoto, T. M. (2002). O brincar e suas teorias. São Paulo: Pioneira-Thomson Learning.

Jou, G. \& Sperb, T. M. (1999). Teoria da mente: diferentes abordagens. Psicologia: Reflexão $e$ Crítica, v. 12 n.2, 287-306. 
Leme, M. S. S. (2005). Aquisição do conhecimento. Boletim Psicologia, v.55 n.123, 233-239.

Lucariello, J. (1995). Mind, culture, person: elements in a cultural psychology. Human Development, 38, 2-18.

Meira, A. M. (2003). Benjamin, os brinquedos e a infância contemporânea. Psicologia \& Sociedade, v.15 n.2, 74-87.

Ministério da Educação e do Desporto, Secretaria de Educação Fundamental (1998). Referencial Curricular Nacional para a Educação Infantil. Brasília: MEC.

Oliveira, Z. (1996). Interações infantis em creche e a construção de representações sociais de gênero. Em M.I.Pedrosa (Org.), Coletânea da ANPEPP: Investigação da criança em interação social, v.1 n.4, 49-67. Recife: Editora Universitária da UFPE.

Packer, M. (1994). Cultural work on the kindergarten playground: Articulating the ground of play. Human Development, 37, 259-276.

Palmieri, M. (2003). Cooperação, competição e individualismo: Uma análise microgenética de contextos de desenvolvimento na pré-escola. Tese de Doutorado, Universidade de Brasília: Brasília.

Pedrosa, M. I. (1996). A emergência de significados entre as crianças nos anos iniciais de vida: Coletânea da ANPEPP: Investigação da criança em interação social, v.1 n.4, 49-67. Recife: Editora Universitária da UFPE.

Piaget, J. (1978). A formação do símbolo na criança: imitação jogo e sonho, imagem e representação. Rio de Janeiro: Zahar.

Piaget, J. (1987). O Nascimento da Inteligência na Criança. Rio de Janeiro: Guanabara.

Pontes, F. A. R. \& Magalhães, C. C. (2003). A transmissão da cultura da brincadeira. Psicologia: Reflexão e Crítica, v.6 n.1, 117-124.

Siaulys, M. O. C. (2005). Brincar para todos. Brasília: MEC/SEESP.

Sperb. T. M. \& Conti. L. (1998). A dimensão metarepresentativa da brincadeira de faz-de-conta.
Cadernos de Psicologia e Educação Paidéia, v.8 n.14/15, 74-90.

Spodek, B. \& Sarasho, O. N. (1998). Ensinando crianças de três a oito anos. Porto Alegre: Artmed.

Tobin, J. J., Wu, D. Y. H. \& Davidson, D. H. (1989). Preschool in three cultures: Japan, China and the United States. New Haven: Yale University Press.

Valsiner, J. (1988). Ontogeny of co-construcion of culture within socially organized environmental settings. In J. Valsiner (Ed.), Child development within culturally structured environments, 2, 283297. New Jersey: Ablex Publishing Corporation.

Valsiner, J. (1989). Human development and culture. The social nature of personality and its study: Lexington, MA: Lexington Books.

Valsiner, J. (1994). Bidirectional cultural transmission and construtive sociogenesis. In W. de Graf \& R. Maier (Eds.), Sociogenesis reexamined (pp. 47-70). New York: Springer.

Valsiner, J. (1998). The guided mind. Cambridge, MA: Harvard University Press.

Valsiner, J. (2000). Culture and development. In J. Valsiner (Ed.), Culture and human development (pp.48-62). Londres: Sage.

Vygotsky, L. (1984). Pensamento e linguagem. São Paulo: Martins Fontes.

Vygotsky L. (1987). História del desarollo das funciones psiquicas superiores. La Habana: Ed. Científico Técnica.

Vygotsky, L. (1998). A formação social da mente. São Paulo: Martins Fontes. 